7. Reprod. Fert. (1968) 16, 511-514

\title{
OBSERVATIONS ON THE ACROSOMAL CAP OF FIXED AND UNFIXED BOVINE SPERMATOZOA
}

\author{
R. G. SAACKE AND C. E. MARSHALL \\ Department of Dairy Science, Virginia Polytechnic Institute, \\ Blacksburg, Virginia, U.S.A.
}

(Received 11th March 1968)

The acrosomal cap of mammalian spermatozoa has received considerable attention from investigators using both light and electron microscopy. Recently, a comprehensive review of the subject has been published (Hancock, 1966). The structure of the acrosomal cap has been difficult to describe due to alterations which the cap undergoes during cell ageing, or after cell death (Hancock, 1953), and the labile nature of the acrosomal cap to chemical or physical processes involved in tissue preparation for microscopy (Bishop \& Austin, 1957). The relationship of acrosome morphology and its alteration to the potentially fertile, motile, immotile or dead cell, as well as the sequence of alteration, must be more clearly understood before the role of this structure in fertilization can be fully evaluated.

This report summarizes our observations on freshly collected bovine spermatozoa examined by light and electron microscopy following fixation and by differential interference contrast without fixation. The use of differential interference-contrast microscopy provides a new means by which observations of the acrosome can be made on unfixed cells without the complication of fixation or processing artifacts.

Semen was collected from Holstein bulls by means of an artificial vagina. Ejaculates used had, at least, a volume of $3 \mathrm{ml}$, an initial motility of $60 \%$ and a sperm concentration of $700 \times 10^{6} / \mathrm{ml}$. For electron microscopy, single ejaculates from three different bulls were pooled, and semen was prepared from both raw and diluted aliquots.

Dilution was in either previously heated skimmed milk or $2.9 \%$ solution of sodium citrate dihydrate. Diluted semen contained $20 \times 10^{6}$ motile sperm $/ \mathrm{ml}$. Spermatozoa were centrifuged from the diluted or raw semen at $4^{\circ} \mathrm{C}$ for 30 min at $750 \mathrm{~g}$. The loose pellet of spermatozoa was transferred to semi-solid $2.5 \%$ agar at $29^{\circ} \mathrm{C}$. The agar was permitted to solidify at room temperature following transfer. This provided a means for handling the spermatozoa through dehydration (Blom \& Birch-Anderson, 1960). Fixation was in 1\% osmium tetroxide solution buffered at $\mathrm{pH} 7.2$ to $7 \cdot 4$ with veronal-acetate (Palade, 1952) containing sucrose (Caulfield, 1957). Pellets were dehydrated in ethanol and embedded in EPON-812. The agar was removed following dehydration. Thin sections were stained with uranyl acetate and lead citrate. 
For light microscopy, Giemsa-stained smears were prepared from the raw semen of more than twenty ejaculates from ten different bulls according to the procedure outlined by Hancock (1953). Unfixed cells of more than twenty ejaculates each were suspended in $2.9 \%$ sodium citrate dihydrate or previously heated skimmed milk and examined at $37^{\circ} \mathrm{C}$ (using a stage incubator) by differential interference-contrast microscopy after Nomarski.

The types of acrosomal cap morphology found in raw and diluted semen based on electron micrographs were arranged in order of deterioration (Pl. 1, Figs. 1 to 4). Dilution did not seem to have any apparent effect on spermatozoan structure. The components of the intact acrosomal cap are labelled in Plate 1, Figs. 1A and 1B. Examination of over 800 electron micrographs indicates that deterioration generally occurred in the following sequence: (1) loss of apical ridge, breakdown of cell membrane, and slight to severe swelling of the anterior acrosomal cap (Pl. 1, Figs. 2 and 3); (2) ruffling followed by breakdown of the outer membrane of the anterior acrosomal cap with the posterior region remaining intact as the equatorial segment (Pl. 1, Figs. 3 and 4 ); (3) loss of moderately electron-dense ground substance in the anterior acrosomal cap (Pl. 1, Fig. 4). The predominant cell type $(>50 \%)$ was represented by the cell in Pl. 1, Fig. 1A having an intact cell membrane, acrosomal cap, apical ridge and lacking a distinct equatorial segment. On occasion, deterioration of the outer membrane of the acrosomal cap preceded breakdown of the cell membrane (Pl. 1, Fig. 1C). However, once the acrosome reached the stages represented by Pl. 1, Figs. 3 and 4, a cell membrane was never observed. When fresh ejaculates

\section{EXPLANATION OF PLATE 1}

Fics. 1 to 4 . Electron micrographs of sagittal sections of the bovine sperm head showing stages of acrosomal deterioration and formation of the equatorial segment.

Fig. IA. Section through entire sperm head showing the nucleus (N), intact acrosomal cap (AC), apical ridge (AR) and cell membrane (CM). The junction of the posterior edge of the acrosomal cap and anterior edge of the postnuclear cap forms the nuclear ring (NR). The postnuclear cap is apparent under the cell membrane in the posterior half of the head. The equatorial segment, not yet apparent, will form between the point of acrosomal swelling $(E)$ and the nuclear ring. $(\times 23,000)$

FIG. 1B. Section showing apical ridge (AR) and layers of the acrosomal cap. The inner membrane (IM) and outer membrane (OM) are continuous at the posterior margin of the cap, thereby completely surrounding the acrosomal ground substance (AS). $(\times 33,000)$

Fic. 1C. Early stage in deterioration of outer membrane of anterior acrosome (arrow) prior to swelling and loss of cell membrane.

Frc. 2. Swelling of anterior acrosomal cap yielding equatorial segment (ES). Acrosomal ground substance (arrow) is apparent under the outer membrane and is probably lost with deterioration of this membrane. $(\times 23,000)$

FIGs. 3 and 4. Late stages in deterioration of the outer membrane of the anterior acrosome and equatorial segment formation. Acrosomal ground substance has dispersed and cell membranes are absent.

Fics. 5 to 8. Light micrographs of fixed, Giemsa-stained spermatozoa arranged in order of acrosomal cap deterioration. Note increased staining intensity and formation of the equatorial segment followed by a loss of staining intensity in the anterior region. $(\times 2400)$

FIGs. 9 to 12. Interference-contrast micrographs of unfixed spermatozoa arranged in order of acrosomal cap deterioration. Note apical ridge (arrow). This was characteristic of all motile cells. Loss of the apical ridge, swelling of the anterior acrosome, formation of the equatorial segment and deterioration of the outer membrane of the anterior acrosome could be observed in individual cells. $(\times 2300)$ 
PLATE 1

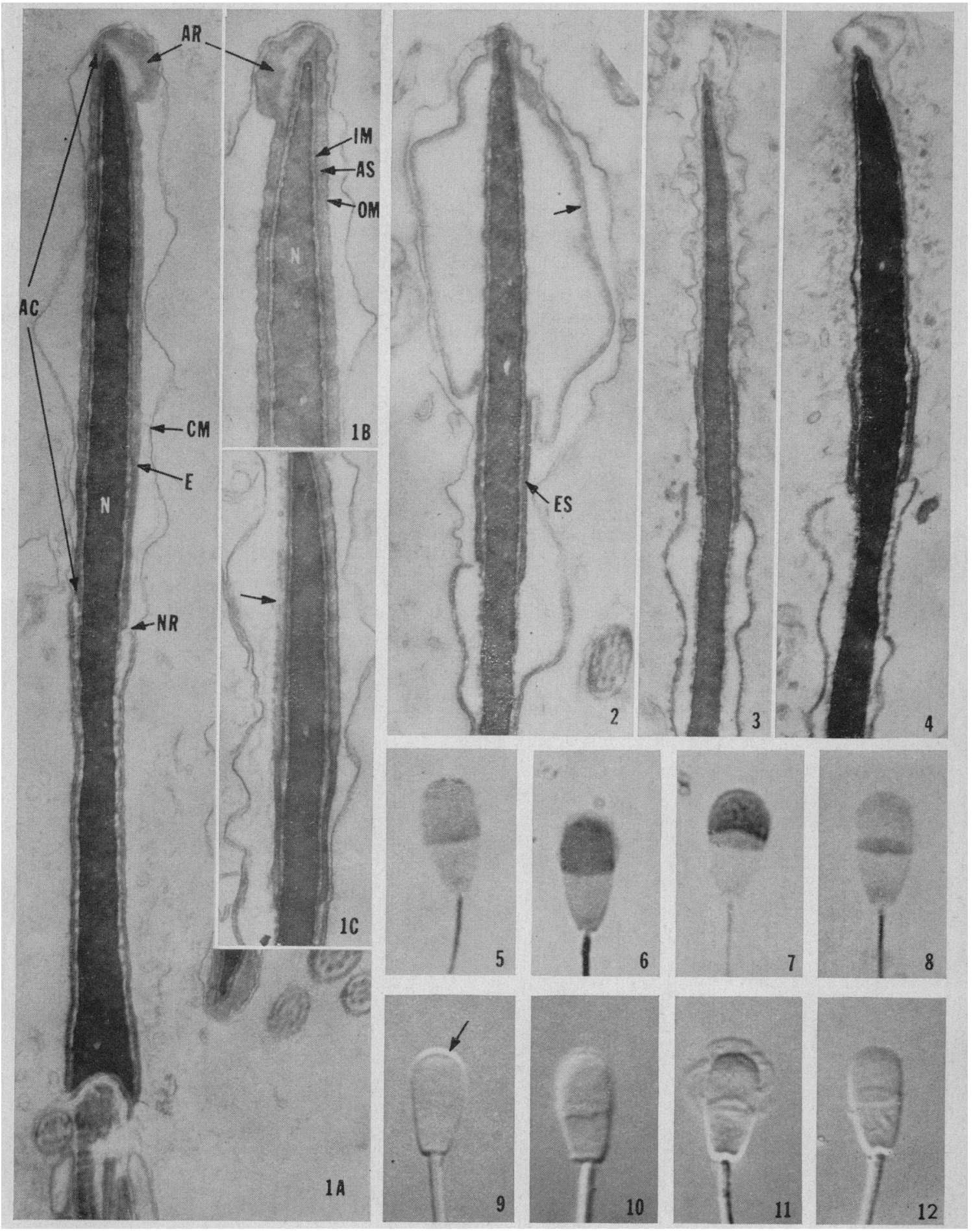

(Facing p. 512) 
were examined by light microscopy following Giemsa staining, acrosomal types comparable to those reported by Hancock (1953) and Onuma (1963) were found and are arranged in order of deterioration (Pl. 1, Figs. 5 to 8). The predominant cell found is represented in Pl. 1, Fig. 5. The order of deterioration is characterized by the following: (1) increased stainability of acrosomal cap and formation of the equatorial segment (Pl. 1, Figs. 6 and 7); (2) loss of stain intensity in the anterior acrosomal cap and retention of stain in the posterior region or equatorial segment (Pl. 1, Fig. 8). In general, deterioration observed in the stained preparations appeared to follow that expected from structural alterations indicated from electron micrographs with the exception of the increased stainability (Pl. 1, Figs. 6 and 7). However, this could be a product of cell membrane breakdown and initial deterioration of the anterior acrosomal cap, thus providing greater accessibility of the stain to the acrosomal ground substance. The continued breakdown of these membranes, however, ultimately results in the leakage or dispersion of the acrosomal ground substance and loss of staining reaction (Pl. 1, Fig. 8).

Using differential interference-contrast microscopy on unfixed semen smears, the relationship of acrosomal morphology to the motile and immotile cell as well as the sequence of alteration within individual cells could be observed. The sequence of acrosomal alterations using this optical system is arranged in order of deterioration (Pl. 1, Figs. 9 to 12). The motile cell was always characterized by an intact acrosomal cap with a distinct apical ridge (Pl. 1, Fig. 9). This was also the predominant cell type of the fresh ejaculates. Immotile cells were composed of those having an acrosomal cap similar to the motile cell as well as those in all stages of deterioration. The order of deterioration observed with this system was as follows: (1) loss of apical ridge with slight swelling of the acrosome and appearance of the nuclear ring. After cessation of motility, this alteration, once initiated, occurred quickly, providing a sharp transition (Pl. 1, Fig. 10); (2) formation of the equatorial segment with continued swelling of the acrosome (Pl. 1, Fig. 11); (3) loss of anterior acrosomal cap (outer membrane) by dissolution or lifting off and retention of posterior acrosomal cap or the equatorial segment (P1. 1, Fig. 12). Thus, the general sequence of acrosomal alterations proposed from observation of fixed cells seems essentially correct. Both light and electron microscope observations support Hancock's (1953) hypothesis that the alterations are either post mortem or occur immediately before cell death, on the evidence that only spermatozoa having lost motility show acrosomal alteration and that in fresh ejaculates, unaltered acrosomal caps predominate. In fresh ejaculates, however, it should be mentioned that there are unaltered acrosomal caps on immotile cells, perhaps suggesting that these may again resume motility.

Thus, it appears that the differential interference-contrast microscope reveals in unfixed cells acrosomal morphology and alteration heretofore quite speculative in origin and relationship to cell viability. Future studies in sperm physiology as well as pathology (acrosomal abnormalities) should be aided by this optical system. 


\section{REFERENCES}

Bishop, M. W. H. \& Austin, C. R. (1957) Mammalian spermatozoa. Endeavour, 16, 137.

Blom, E. \& Brrar-Andersen, A. (1960) The ultrastructure of the bull sperm. I. The middle piece. Nord. VetMed. 12, 261.

CAulfiEld, J. B. (1957) Effects of varying the vehicle for osmium in tissue fixation. F. biophys. biochem. Cytol. 3, 827.

Hancock, J. L. (1953) The spermatozoa of sterile bulls. F. exp. Biol. 30, 50.

HANCOCK, J. L. (1966) The ultrastructure of mammalian spermatozoa. In: Advances in Reproductive Physiology, Vol. I, p. 125. Ed. Anne McLaren. Logos Press, London.

Onuma, H. (1963) Studies on the acrosomic system of spermatozoa of domestic animals. VI. The acrosomic system of spermatozoa in fresh semen of bulls and boars and its morphological changes due to storage or the temperature shock. Bull. natn. Inst. Anim. Ind. 3, 105.

Palade, G. E. (1952) A study of fixation for electron microscopy. F. exp. Med. 95, 285. 